\title{
Emerging Epidemics in Transplant: Histoplasmosis, Blastomycosis, and Paracoccidioidomycosis
}

\author{
Jeremy Nel, Anne Lachiewicz, and David van Duin
}

\section{Contents}

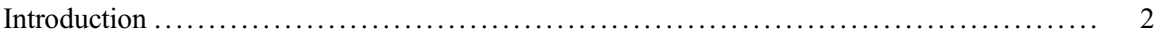

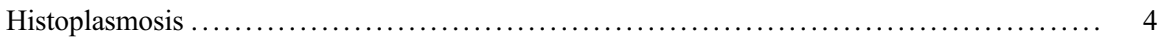

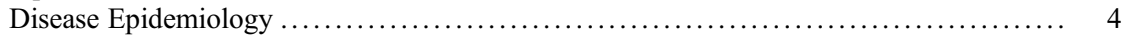

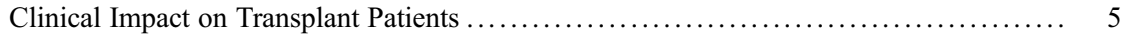

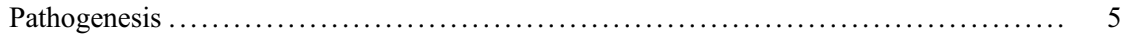

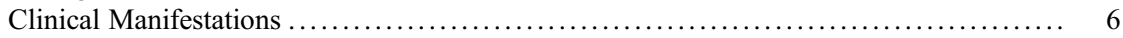

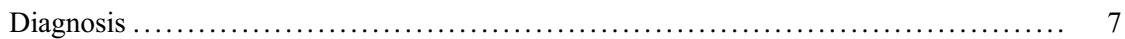

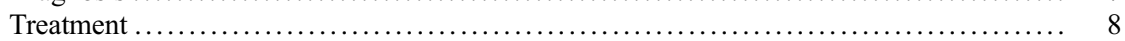

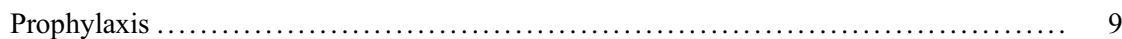

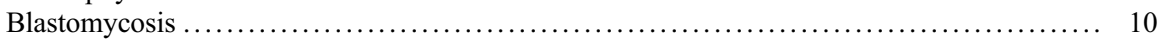

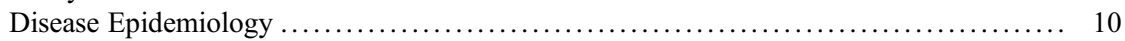

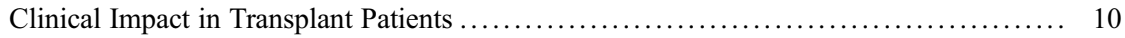

Pathogenesis and Clinical Manifestations ...................................... 11

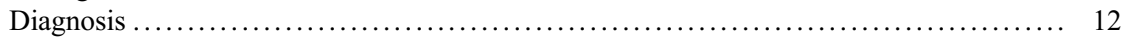

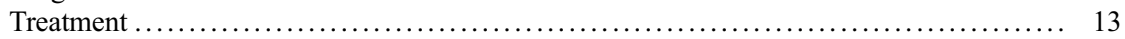

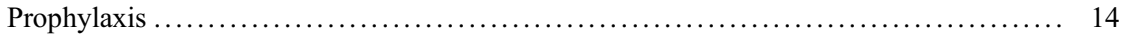

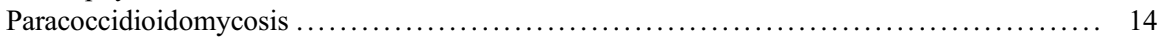

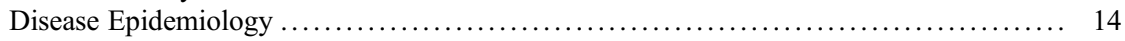

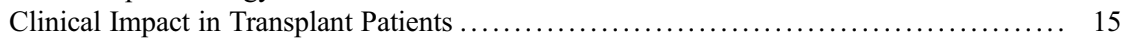

Pathogenesis and Clinical Manifestations ................................... 15

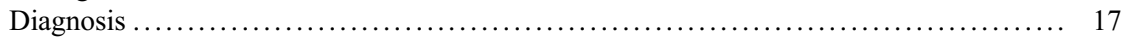

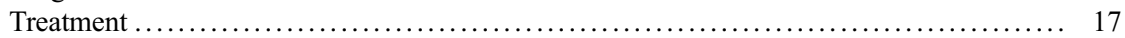

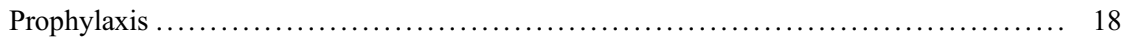

J. Nel

University of the Witwatersrand, Johannesburg, South Africa e-mail: jeremynel@hotmail.com
A. Lachiewicz · D. van Duin (四)
Infectious Diseases, University of North Carolina School of Medicine, Chapel Hill, NC, USA
e-mail: anne_lachiewicz@med.unc.edu; david_vanduin@med.unc.edu 
Common Antifungal Drugs Used to Treat the Endemic Mycoses ..................... 19

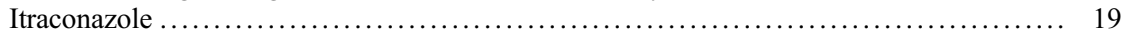

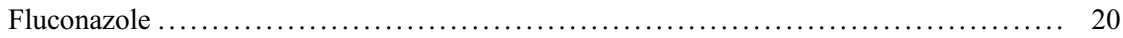

Amphotericin B ........................................................ 20

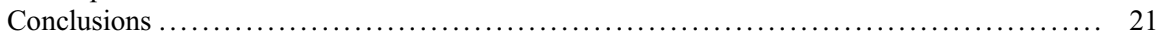

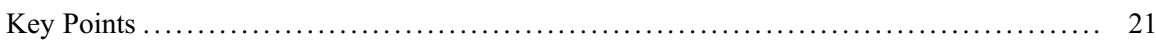

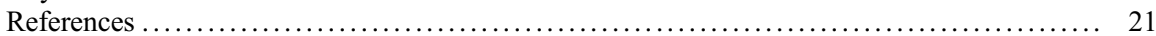

\section{Abstract}

The endemic fungi are a group of thermally dimorphic fungi that occupy specific defined environmental ranges. They count Histoplasma, Blastomyces, Paracoccidioides, Coccidioides, Talaromyces, Emergomyces, and Sporothrix among their number. In the environment, they exist as molds, and at body temperature, they transform into their pathogenic yeast form (or, in the case of coccidioidomycosis, into a specialized structure called a spherule). Histoplasma, Blastomyces, and Paracoccidioides are covered in this chapter. Transplant recipients are at increased risk for severe and disseminated infection with these pathogens. Histoplasmosis and blastomycosis usually manifest as pulmonary disease. Extrapulmonary disease can occur with or without concomitant pulmonary disease in immunocompromised hosts. Commonly infected sites include the liver, spleen, lymph nodes, bone marrow, gastrointestinal tract, and skin. Skin involvement is especially common in blastomycosis. Paracoccidioidomycosis may present in an acute disseminated form in young patients. However, in $90 \%$ of symptomatic paracoccidioidomycosis, pulmonary chronic disease is observed, which is a reactivation of prior acquired infection. Oral mucosa and skin are common sites of dissemination in chronic disease. Diagnosis of endemic mycoses is difficult and often delayed. Combining various diagnostic modalities is usually needed. The treatment of choice for all the endemic mycoses are amphotericin B and the azoles. In general, treatment must be given for a prolonged period (frequently a year or more) in order to prevent a relapse.

\section{Keywords}

Histoplasmosis $\cdot$ Blastomycosis $\cdot$ Paracoccidioidomycosis $\cdot$ Solid organ transplantation $\cdot$ Mycosis

\section{Introduction}

The endemic fungi are a group of thermally dimorphic fungi that occupy specific defined environmental ranges (Fig. 1). They count Histoplasma, Blastomyces, Paracoccidioides, Coccidioides, Talaromyces, Emergomyces, and Sporothrix among their number. In the environment they exist as molds, and at body temperature, they transform into their pathogenic yeast form (or, in the case of coccidioidomycosis, into a specialized structure called a spherule). Histoplasma, Blastomyces, and Paracoccidioides are covered in this chapter. The main form of 


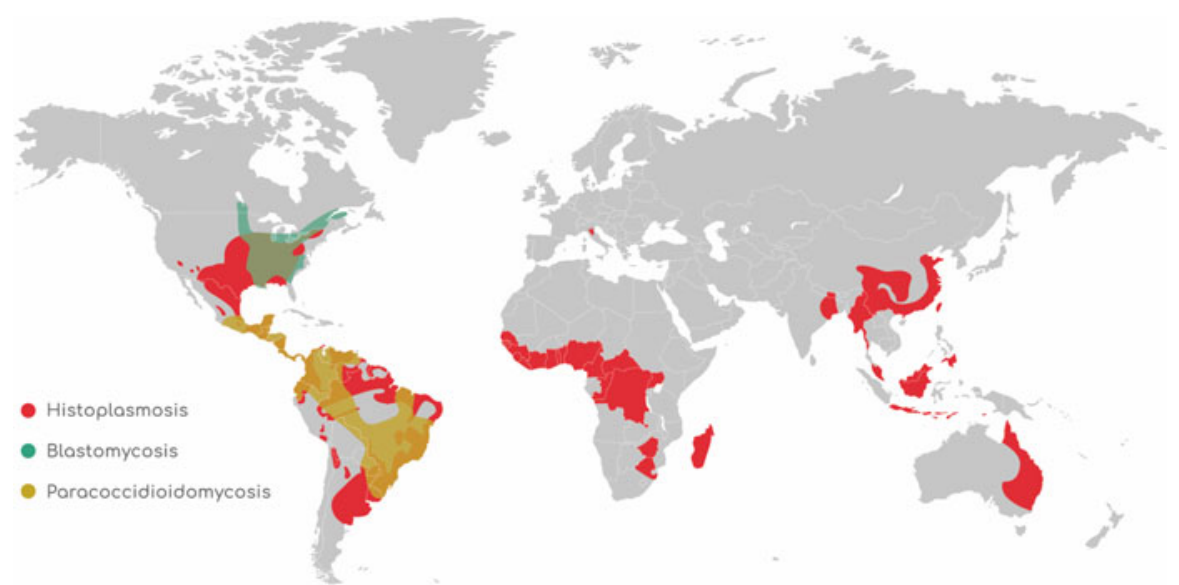

Fig. 1 Approximate areas of endemicity for histoplasmosis, blastomycosis, and paracoccidioidomycosis $[6,86,87]$

acquiring these diseases is by inhaling the mold form's conidia, and this frequently happens after the soil or decaying vegetation that houses the fungus is disturbed. After the conidia are inhaled, the fungus undergoes one of three fates. If the host's innate immunity is strong enough, or the inoculum small enough, the conidia and/or yeasts may be killed outright. If this defense fails, the infection may be able to be controlled by the host's T-cell-mediated immunity, often in a quiescent state within granulomas, from which it may subsequently escape if the host's immunity wanes as, for example, following a transplant. For this reason, disease from one of the endemic mycoses can occur years, sometimes decades, after the patient visited an endemic area. Lastly, if the infection is not able to be sufficiently controlled by the patient's immune system initially, symptomatic disease may occur more immediately, either within one organ system (often the lung) or disseminated more broadly.

The microbiologic diagnosis of endemic mycoses is limited by a relative lack of sensitivity of cultures, difficulty in obtaining the most appropriate samples from patients, and the slow growth of the organism in culture. Therefore, non-culturebased methods of diagnosis such as direct microscopic exam of specimens, antigen assays, and antibody tests are used in conjunction with cultures. Antibody assays often have decreased sensitivity in transplant recipients however. Polymerase chain reaction (PCR) assays are an emerging diagnostic modality, albeit one that is often not commercially available or well studied.

The treatments of choice for all the endemic mycoses are liposomal amphotericin B (given up front for severe disease) and the azoles. While the newer azoles such as posaconazole or isavuconazole show some promise, the bulk of the evidence resides with the older azoles, such as itraconazole, fluconazole, and voriconazole, and there are few direct comparisons available by which to dislodge the latter drugs as frontline agents. In general, treatment must be given for a prolonged period (frequently a year or more) in order to prevent a relapse. 


\section{Histoplasmosis}

\section{Disease Epidemiology}

Histoplasmosis is caused by the fungus Histoplasma capsulatum. Mycelial growth in histoplasmosis is favored in soil in climates with moderate temperatures (between $15{ }^{\circ} \mathrm{C}$ and $40{ }^{\circ} \mathrm{C}$ ), high relative humidity, and a soil $\mathrm{pH}>5.5$ [1]. Growth and sporulation of Histoplasma capsulatum are especially enhanced by the presence of bird and bat guano, which provides a high nitrogen and phosphorus content that can on occasion permit mycelial growth even in the absence of soil [2]. Activities that disturb soil and aerosolize Histoplasma spores can place patients at risk of acquiring histoplasmosis. These activities classically include spelunking, digging in soil where there are bird or bat droppings, cleaning bird coops, and renovating or demolishing buildings that have been colonized by bats or birds [1, 3, 4]. However, Histoplasma conidia may be carried for miles on air currents, and many patients do not have a history of a specific exposure.

The highest incidence of histoplasmosis worldwide appears to be in North America, in an area surrounding the Ohio and Mississippi River Valleys [5, 6]. However, patches of histoplasmosis endemicity are spread throughout the world. A large number of endemic cases have been reported from Mexico, Central America, and the majority of South American countries (Fig. 1). In areas of Brazil, skin reactivity to histoplasmin antigens (reflecting prior exposure to the fungus) has been reported in nearly $90 \%$ of inhabitants tested in some areas of the country [5]. Cases of histoplasmosis have also been identified from the majority of African countries, though the picture is somewhat clouded by the existence of two variants there, with an "African" variant, Histoplasma capsulatum var. duboisii, prevalent in the western parts of the continent. Histoplasma capsulatum var. capsulatum, the variant present elsewhere in the world, is found in Africa's southern parts, and the two variants coexist in the intervening areas $[6,7]$. Parts of India and Southeast Asia also appear to be endemic for histoplasmosis, with Malaysia, Thailand, Taiwan, China, and the eastern parts of Australia all reporting endogenously acquired cases and substantial rates of histoplasmin skin hypersensitivity [6]. Histoplasmosis is not generally considered endemic in Europe, with a near $0 \%$ rate of positive skin hypersensitivity assays there and reported cases from Europe generally having been imported from endemic areas elsewhere in the world. However, a small number of potentially autochthonous cases have been described from Italy, Germany, and Turkey [8]. This worldwide distribution of histoplasmosis stands in contrast with the much more geographically restricted ranges of other endemic fungi, such as coccidioidomycosis, paracoccidioidomycosis, and blastomycosis. It is possible that naturally infected bats and birds with long-range migrations may be responsible for Histoplasma capsulatum's wide dispersal to disparate regions of the globe [5].

Surveys of histoplasmin skin hypersensitivity that have identified the traditional endemic areas of the world have been performed in only a small minority of countries, and many such maps are now decades old [9]. Factors like climate change and population migration may have changed these areas since the surveys. Indeed, 
recent evidence suggests that the preferred soil environments in the USA might now include the Missouri River basin, in addition to the Ohio and Mississippi River basins [10]. In addition, soil and climatic conditions that support Histoplasma growth likely exist in many "microenvironments" throughout the world, and thus histoplasmosis should be considered in any patient with a compatible clinical picture, even without travel to one of the classic endemic areas [6]. This dictum is all the more important considering that histoplasmosis has been reported to reactivate up to 50 years after initial exposure, which further clouds the association between the disease and a history of exposure to an endemic area [8].

\section{Clinical Impact on Transplant Patients}

Histoplasmosis causes the greatest burden of disease of all the endemic fungi seen in immunocompromised hosts. The Transplant-Associated Infection Surveillance Network (TRANSNET) reported 48 histoplasmosis cases in solid organ transplant (SOT) recipients and 4 histoplasmosis cases in in hematopoietic cell transplant (HCT) recipients, respectively, from 15 surveillance sites over 5 years from 2001 to 2006 [11]. The cumulative incidence in SOT recipients was $0.1 \%$ for the 12-month period following their transplants. In a high-volume SOT center in Ohio, incidence of post-SOT histoplasmosis was 1 case per 1000 transplant-person-years (95\% confidence interval, 0.6-1.7) [12]. The risk of histoplasmosis is highest in the first year after transplantation, though an increased posttransplant risk is likely to persist indefinitely compared to immunocompetent patients. By way of example, the incidence of histoplasmosis among SOT recipients in Ohio, a known endemic area, was 16 times higher than that of the general population $>65$ years of age in the same state [13]. Mortality from histoplasmosis arising after SOT is approximately $10 \%$, with the bulk of deaths occurring within the first month after diagnosis [11, 14]. In the TRANSNET cohort, there were no deaths at 3 months among the four HCT recipients who developed histoplasmosis.

\section{Pathogenesis}

Aerosolized Histoplasma capsulatum conidia may be inhaled, and microconidia between the sizes of 2 and 4 micrometers are small enough to reach the alveolar spaces. Microconidia that evade the lung's innate defenses develop into the yeast phase of the organism. Macrophages are initially capable of phagocytosing but not killing the organisms, as it takes approximately 10-14 days for the development of the required CD4 T-lymphocyte-mediated immune response [15]. If this immune response is robust enough, the spread of the organism is arrested. Most immunocompetent patients are thus either asymptomatic or have mild, self-limiting respiratory symptoms [4]. Immunocompromised patients, including SOT and HCT recipients, may fail to stop the spread of the organism and present with progressive disseminated disease [15]. 


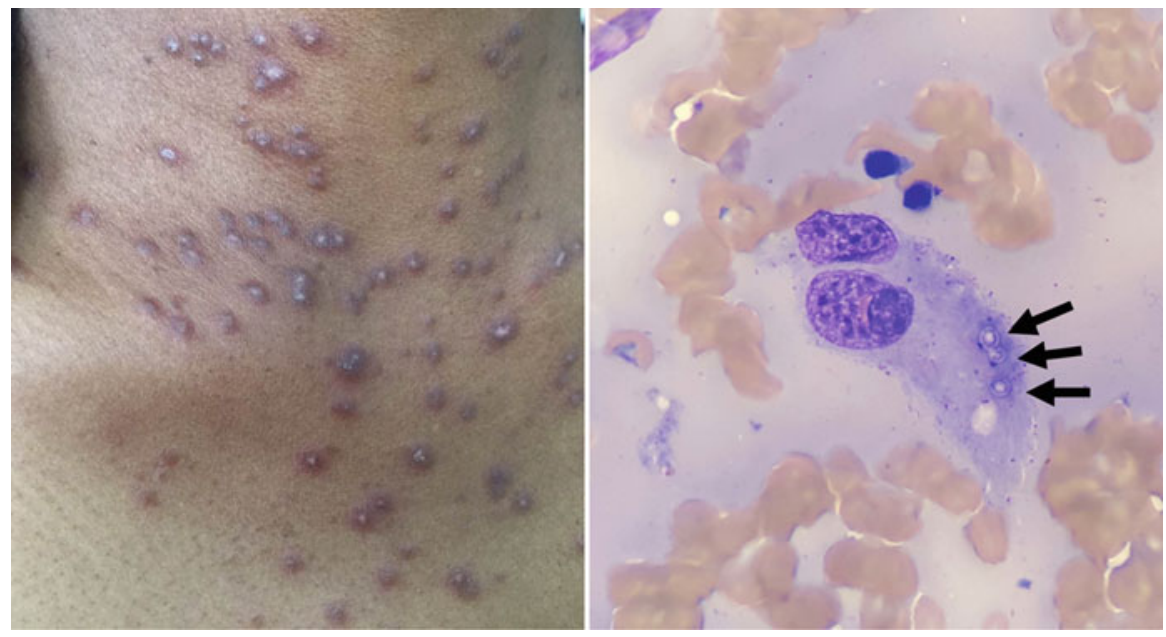

Fig. 2 Histoplasmosis. Left, typical papular rash sometimes seen with disseminated disease. Right, yeast form of histoplasmosis visible on this bone marrow aspirate as small yeasts (arrows) clustered within a macrophage. The pseudocapsule that provides the organism's species name ("capsulatum") is clearly visible but is an artifact of cytoplasmic shrinkage (Wright-Giemsa stain)

Even those patients who do control the infection frequently fail to completely eradicate it. Rather, viable Histoplasma capsulatum organisms may be walled off inside granulomas within the body. Patients who have had prior histoplasmosis exposure, even decades before, are at risk of suffering a reactivation of the disease if their immunity subsequently declines, whether from SOT, HCT, immunosuppressant medications, old age, HIV, or other immunosuppressing conditions [15]. In many cases, whether a case of histoplasmosis represents disease reactivation or a new acquisition can be difficult to determine, although some evidence suggests that new acquisition may predominate $[13,16,17]$.

SOT recipients may acquire the disease from an infected allograft. To date this method of transmission remains extremely rare, with only a handful of cases in the literature $[18,19]$.

\section{Clinical Manifestations}

Consistent with Histoplasma capsulatum's pulmonary route of acquisition and subsequent engulfment by macrophages, the predominant organs involved are the lungs and the lymphoid-rich tissues. The better the patient's cell-mediated immunity, the greater the chance that disease remains confined to the lungs. Those with a modest exposure to Histoplasma capsulatum may develop a subacute or chronic pneumonia or one or more pulmonary nodules that may be incidentally picked up on chest X-ray. Those with a larger exposure can develop an acute pneumonia and acute respiratory distress syndrome. Other less common presentations such as 
broncholithiasis and fibrosing mediastinitis are also possible [3]. SOT and HCT recipients may develop any of the above pulmonary syndromes, but disease more frequently disseminates beyond the lungs; disseminated disease is the rule rather than the exception in these patient subgroups. In the TRANSNET cohort of HCT and SOT recipients mentioned above, $>71 \%$ of cases had demonstrable dissemination at the time of diagnosis [11].

Extrapulmonary disease can occur with or without concomitant pulmonary disease in immunocompromised hosts. Commonly infected sites include the liver, spleen, lymph nodes, bone marrow, gastrointestinal tract, and skin (Fig. 2). Systemic symptoms such as fever, loss of weight, anorexia, and fatigue are common. Clinical signs seen with disseminated disease include hepatomegaly, splenomegaly, lymphadenopathy (which may sometimes be massive), and the effects of cytopenias [3]. Hemophagocytic lymphohistiocytosis is also a recognized complication of disseminated histoplasmosis.

\section{Diagnosis}

No diagnostic test for histoplasmosis has adequate sensitivity to be used in isolation. Rather, multiple tests should be performed in parallel, guided by the sites of involvement in the individual patient. Urine histoplasma antigen assays have the highest sensitivity of any single diagnostic test in disseminated histoplasmosis, with an estimated sensitivity of $\sim 93 \%$ in SOT recipients. Serum antigen testing is somewhat less sensitive (estimated $80 \%$ sensitivity). Antigen testing may also be positive in bronchoalveolar lavage (BAL) fluid and cerebrospinal fluid (CSF), when these areas are involved. However, the specificity of the antigen test is limited by cross-reaction with similar antigens from other endemic fungi [20]. Crossreaction with Aspergillus antigens has also been reported in solid organ transplant patients [21]. Antibody assays are insensitive in histoplasmosis in general and particularly so in transplant recipients. Cultures from blood and any other infected site (e.g., bronchoalveolar lavage fluid, skin, liver, lymph nodes) are generally positive in $>60 \%$ of cases [22]. However, the utility of cultures is further limited by the fact that the organism typically takes $2-4$ weeks for adequate growth to permit identification [3]. Histologic specimens taken from the lungs, lymph nodes, liver, bone marrow, skin, or other involved organs may reveal typical clusters of small $(2-4 \mu \mathrm{m})$ yeasts intracellularly within macrophages and other phagocytes (Fig. 2) [23]. This may permit a provisional diagnosis. Polymerase chain reaction (PCR) is a promising emerging diagnostic modality that offers the potential to obtain rapid and highly specific results. However, trials to date have used a variety of methodologies and technologies, with correspondingly varying results, preventing a firm recommendation for the use of PCR-based diagnostics [24-26]. 


\section{Treatment}

Transplant recipients with histoplasmosis should generally be considered to have disseminated disease unless proven otherwise. In most cases, amphotericin B is advised for 1-2 weeks initially, followed by itraconazole for at least 12 months [27]. Lipid formulations of amphotericin are preferred over amphotericin B deoxycholate, primarily because of decreased toxicity. In addition, histoplasmosis remains the only condition for which the liposomal form of amphotericin has also been shown to be more efficacious than the deoxycholate form [28]. Severely ill patients may have attendant acute kidney injury, but this should not dissuade clinicians from using lipid formulations of amphotericin initially in such cases. Indeed, renal dysfunction may improve if the infection is rapidly brought under control with amphotericin.

Following an initial 1-2 weeks of amphotericin therapy, the patient may be transitioned to azole therapy to complete a minimum of 12 months of therapy. Itraconazole is the preferred azole for use in histoplasmosis. In mild to moderate cases of disease, itraconazole alone, without amphotericin, may even be sufficient as therapy [29]. Measuring blood levels of itraconazole is recommended, as its bioavailability may often be impaired by gastric conditions, and itraconazole is also frequently both a cause and target of drug-drug interactions (see section "Common Antifungal Drugs Used to Treat the Endemic Mycoses") [27].

Itraconazole appears superior to fluconazole for the treatment of disseminated histoplasmosis. In vitro data shows a greater potency for the former drug, and acquired immunodeficiency syndrome (AIDS) patients with mild-moderate disseminated disease who were treated with itraconazole had a greater response rate than those treated with fluconazole in a similar trial (85\% vs. 70\%) [29-31]. The relapse rate with fluconazole was also substantially higher than that seen with itraconazole in these trials, driven by the development of resistance while on therapy [30]. This phenomenon was not seen with itraconazole.

The role of other azoles in the treatment of histoplasmosis has not been well studied. On the basis of in vitro data, posaconazole seems more potent and less prone to developing resistance than voriconazole [32]. Other in vitro data suggest that isavuconazole is an extremely potent drug, and like posaconazole, its potency does not appear to be affected by the development of fluconazole resistance. Furthermore, isavuconazole offers excellent bioavailability that may preclude the need for routinely measured drug levels. However, clinical experience with posaconazole, voriconazole, or isavuconazole in treating histoplasmosis patients is decidedly limited to date, and thus their role is currently relegated to salvage therapy in patients who have failed or are intolerant of itraconazole therapy [27, 33].

Of note, the yeast form of $H$. capsulatum is not susceptible to the echinocandins, which therefore have no role in therapy [34].

Symptoms of histoplasmosis may take several weeks to fully resolve, though some overall clinical improvement is usually seen within a week. Histoplasma antigen levels may be monitored serially to assess response to therapy. A failure of the antigen level to decline on treatment may represent treatment failure. Antigen levels should also be checked for 6-12 months after completing therapy to check 
Table 1 Role of diagnostic tests in histoplasmosis, blastomycosis, and paracoccidioidomycosis in transplant recipients

\begin{tabular}{l|l|l|l}
\hline & Histoplasmosis & Blastomycosis & Paracoccidioidomycosis \\
\hline Microscopy & $\begin{array}{l}\text { Small }(2-4 \mu \mathrm{m}) \text { yeasts } \\
\text { clustered within } \\
\text { macrophages, with } \\
\text { pseudocapsule }\end{array}$ & $\begin{array}{l}\text { Large }(10-15 \mu \mathrm{m}) \\
\text { yeasts with thick } \\
\text { walls and broad- } \\
\text { based budding }\end{array}$ & $\begin{array}{l}\text { Variably sized yeasts } \\
(4-60 \mu \mathrm{m}) \text { arranged as a } \\
\text { central parent yeast with } \\
\text { multiple other yeasts } \\
\text { budding off }\end{array}$ \\
\hline Cultures & $\begin{array}{l}\text { Sensitive but growth } \\
\text { typically takes 2-4 weeks }\end{array}$ & $\begin{array}{l}\text { Sensitive but growth } \\
\text { typically takes } \\
\text { 2-4 weeks }\end{array}$ & $\begin{array}{l}\text { Sensitive but growth } \\
\text { typically takes 2-4 weeks }\end{array}$ \\
\hline Serology & $\begin{array}{l}\text { Limited value }- \text { poor } \\
\text { sensitivity }\end{array}$ & $\begin{array}{l}\text { Limited value }- \text { very } \\
\text { poor sensitivity }\end{array}$ & $\begin{array}{l}\text { Moderate sensitivity in } \\
\text { transplant patients. Serial } \\
\text { measurements can be used } \\
\text { to follow treatment } \\
\text { response }\end{array}$ \\
\hline $\begin{array}{l}\text { Antigen } \\
\text { test }\end{array}$ & $\begin{array}{l}\text { Urine antigen test has } \\
\text { sensitivity }>90 \% \text {. Blood } \\
\text { antigen test has sensitivity } \\
\text { of } \sim 80 \% \text {. Some cross- } \\
\text { reaction with other fungi }\end{array}$ & $\begin{array}{l}\text { Urine antigen test has } \\
\text { sensitivity of } \\
76-93 \% \text {. Cross- } \\
\text { reaction with other } \\
\text { fungi seen }\end{array}$ & $\begin{array}{l}\text { Not commercially } \\
\text { available }\end{array}$ \\
\hline
\end{tabular}

for a relapse. In general, antigen levels should be negative at the end of treatment, though some patients with persistent low-level antigenuria without evidence of active disease have had good clinical outcomes when their treatment was stopped $[27,35]$.

\section{Prophylaxis}

SOT or HCT recipients should avoid activities known to be high risk for acquiring histoplasmosis, such as those mentioned previously. Primary prophylaxis has only been studied in patients with advanced HIV, where a daily dose of itraconazole more than halved the incidence of histoplasmosis over a median follow-up period of 16 months in an endemic area [36]. Based on expert opinion however, the Infectious Diseases Society of America (IDSA) recommends prophylaxis only in situations where the incidence of histoplasmosis is greater than 10 cases per 100 patient years.

The role of secondary prophylaxis after transplant is also somewhat unclear. Patients with a history of previous histoplasmosis, or radiologic or serologic evidence of past disease, are at risk of reactivation in the posttransplantation period due to their profound immunosuppression. However, the risk of reactivation appears low. Not a single case of histoplasmosis was diagnosed in over 550 HCT and SOT recipients over a mean follow-up of 16 months in a hyperendemic area. This cohort included patients with radiographic and serologic evidence of past disease. Another important consideration is that the urine histoplasma antigen is a useful screening test for disease reactivation. Thus, instead of itraconazole prophylaxis, an alternative 
strategy is to measure urine histoplasma antigen levels every 2-3 months during the intensive phase of the patient's immunosuppression regimen [27]. Similarly, patients who develop histoplasmosis for the first time after transplantation probably do not require secondary prophylaxis and should instead have serial urine histoplasma antigen levels mentioned after their treatment course has been completed. Notably, the risk of disease reactivation after appropriate treatment is low, at $<5 \%$ [14].

A related problem involves organ donors with a remote history of histoplasmosis. Though little data exists to guide decision-making in this scenario, a suggested approach is outlined in Table 2.

\section{Blastomycosis}

\section{Disease Epidemiology}

Recent phylogenetic work has revealed that blastomycosis is caused by one of two species, Blastomyces dermatitidis and Blastomyces gilchristii. The natural habitat of the organism has been far harder to elucidate than that of the other endemic fungi, for two reasons. Firstly, it has proven very difficult to isolate the fungus from environmental sources, and secondly, there are no adequately sensitive and specific serologic tests or skin test reagents [37]. Despite these limitations, autochthonously acquired cases have historically clustered around the Great Lakes area on both the US and Canadian sides, as well as the Ohio, Mississippi, and St Lawrence River basins (Fig. 1) [37]. Indeed, two outbreak studies where Blastomyces was ultimately cultured suggest that soil and wooded areas surrounding rivers and lakes may be the organism's favored habitat [38, 39]. The blastomycosis-endemic areas overlap extensively with those for histoplasmosis, though the former are more extensive. Outside of North America, endogenously acquired cases have been reported from India and several African countries [40, 41].

Similar to histoplasmosis, risk factors for acquiring the disease include activities that disturb the soil and thereby aerosolize Blastomyces conidia. Known associations include camping, forestry work, fishing, cutting trees, or clearing brush in endemic areas $[16,38,39]$.

\section{Clinical Impact in Transplant Patients}

The TRANSNET surveillance network identified just 9 cases of blastomycosis in transplant recipients (compared to 52 cases of histoplasmosis) over a 5-year period [11]. All nine cases were seen in SOT recipients, though rare cases of blastomycosis in HCT recipients have been described elsewhere [42]. Similarly to histoplasmosis, the majority of cases occur within the first year after transplantation [11]. Mortality estimates for SOT recipients with blastomycosis have ranged from $0 \%$ to $36 \%[11,43,44]$. 


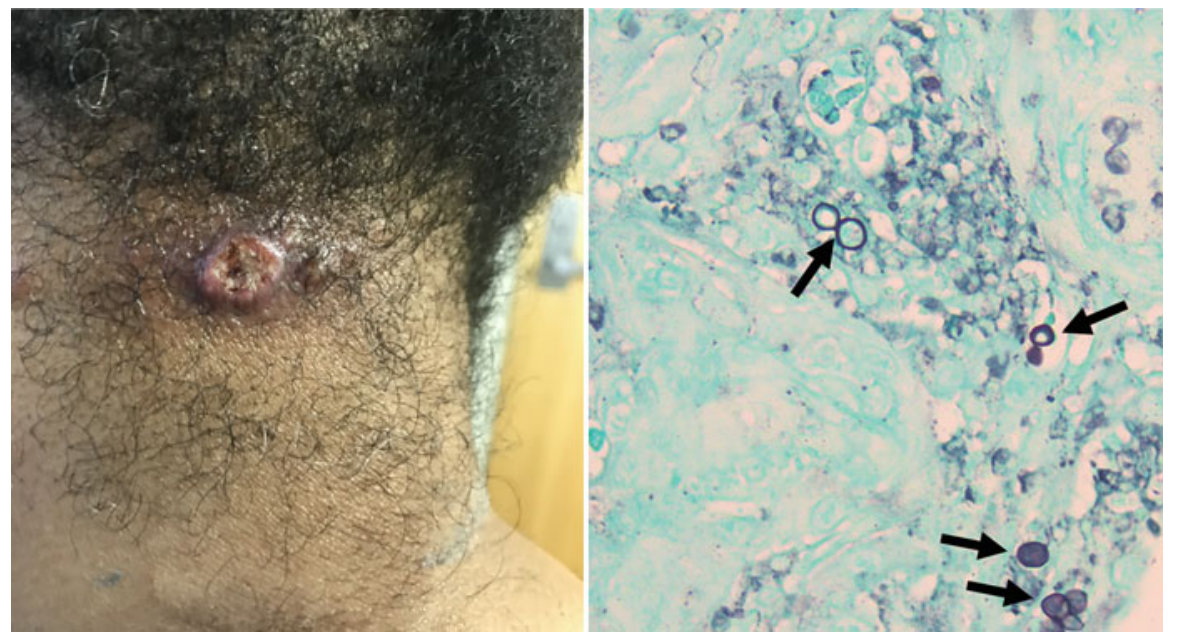

Fig. 3 Blastomycosis. Left, typical skin lesions of disseminated blastomycosis, with ulcerating nodules and papules. Right, histopathologic image of the same skin lesion, showing large yeasts with broad-based budding (arrows) (Grocott-Gomori methenamine silver stain)

\section{Pathogenesis and Clinical Manifestations}

Blastomyces conidia, possibly aerosolized during soil disturbances, are inhaled and reach the alveoli. If they survive destruction by the lung's neutrophils, monocytes, and macrophages, the shift in ambient temperature signals to the conidia to develop into the yeast form. As with histoplasmosis, this form is harder to kill due to its size (which prevents phagocytosis by neutrophils), its thicker cell wall, and the expression of various virulence factors. In the case of blastomycosis, the latter include BAD-1, which mediates attachment to macrophages and also shifts the cellmediated immune response away from the Th1 response that is required to eliminate the infection [45]. If the patient's immune response is not adequate to contain the organism within the lungs, disseminated infection may occur. In addition, the organism may be held in check in a dormant state by the patient's immune system, allowing reactivation should the patient's immune competency decline, such as what occurs in SOT or HCT recipients. Remote reactivation as long as 40 years after initial infection has been described [46]. No cases of graft-derived blastomycosis have been reported to date.

As with all the endemic fungi, clinical manifestations depend on the interplay between host immunity and the inoculum size. Patients with a robust immune response may clear the organism before any symptoms develop. Indeed, approximately half of immunocompetent patients are asymptomatic. However, transplant recipients are more likely to develop symptomatic pulmonary disease - the lungs are involved in $80-100 \%$ of cases $[43,44]$. Transplant recipients also seem predisposed to have a more severe pulmonary course than immunocompetent patients. Rates 
of acute respiratory distress syndrome (ARDS) and early mortality are higher, and patients who do recover may have substantial residual lung damage [11, 43, 44].

Transplant patients may also have greater rates of disseminated disease [43]. When the disease spreads beyond the lungs, the next most commonly involved site is the skin, though multiple pustules or ulcers are more common than the classic verrucous lesions seen in immunocompetent patients (Fig. 3) [47]. Other clinical manifestations include lytic bone lesions, prostatitis, epididymitis, meningitis, or cerebral abscesses. Interestingly, CNS disease with blastomycosis appears to be far less common among SOT recipients than it is among patients with AIDS [48]. Importantly, at the time when extrapulmonary symptoms appear, pulmonary findings can be minimal or even absent [49].

\section{Diagnosis}

Blastomycosis is often not considered in a patient's differential diagnosis. In one study in Mississippi, USA, only $5 \%$ of patients with blastomycosis were correctly diagnosed at presentation, and $43 \%$ had a delay in diagnosis of over 1 month, despite the fact that Mississippi is a hyperendemic area [50].

Blastomyces grows readily in appropriate culture media, though, like all dimorphic fungi, it may take up to 4-6 weeks of incubation before it shows adequate growth to permit a diagnosis [49]. The yield from pulmonary specimens is often excellent, with sputum and bronchoalveolar lavage fluid cultures having a sensitivity of approximately $75 \%$ and $92 \%$, respectively [51]. Cultures from the skin and other involved areas are also frequently positive.

Direct examination of culture or biopsies taken from the lung, skin, bone, and other sites is less sensitive but when positive allows for a rapid diagnosis. Blastomyces has a characteristic appearance, namely, that of a large yeast $(10-15 \mu)$ with thick "double-contoured" walls and distinctive broad-based budding (Fig. 3) [23].

A urinary antigen test for blastomycosis is available and has a reported sensitivity of $76-93 \%$. In contrast to histoplasmosis, the test may be more sensitive for pulmonary $(83-100 \%)$ than disseminated disease $(67-89 \%)$ [52, 53]. However, because they share similar galactomannans, this assay may significantly crossreact in the presence of other endemic dimorphic fungi [52]. For this reason, simultaneously performing the blastomycosis urinary antigen in conjunction with the histoplasma antigen may be useful [23].

Serology in blastomycosis is of extremely limited value, owing to very poor sensitivity of both the complement fixation and immunodiffusion assays (as low as $9 \%$ and $28 \%$, respectively). Enzyme immunoassays (EIAs) have better diagnostic accuracy but are not commercially available [23].

PCR offers some promise, but the technique has not been studied in large-scale trials, and so its place in the diagnostic algorithm for blastomycosis remains unclear. 
Table 2 Suggested prophylactic regimens for histoplasmosis, blastomycosis, and paracoccidioidomycosis in transplant recipients

\begin{tabular}{l|l|l}
\hline & $\begin{array}{l}\text { Recipient peri-transplant } \\
\text { (primary) prophylaxis }\end{array}$ & $\begin{array}{l}\text { Secondary prophylaxis for } \\
\text { recipients after completion of } \\
\text { treatment course }\end{array}$ \\
\hline Histoplasmosis & $\begin{array}{l}\text { Donor with localized pulmonary } \\
\text { disease: itraconazole 200 mg } \\
\text { once or twice daily for } \\
\text { 3-6 months } \\
\text { Donor with disseminated } \\
\text { disease: itraconazole 200 mg } \\
\text { once or twice daily for } \\
\text { 12 months [84] }\end{array}$ & $\begin{array}{l}\text { Not routinely indicated. Can } \\
\text { monitor urine antigen level } \\
\text { every 3 months to determine } \\
\text { need. If required, consider } \\
\text { itraconazole 200 mg daily } \\
{[27,84]}\end{array}$ \\
\hline Blastomycosis & $\begin{array}{l}\text { Donor with localized pulmonary } \\
\text { disease: itraconazole 200 mg } \\
\text { once or twice daily for } \\
\text { 3-6 months } \\
\text { Donor with disseminated } \\
\text { disease: itraconazole 200 mg } \\
\text { once or twice daily for } \\
12 \text { months }\end{array}$ & $\begin{array}{l}\text { Not routinely indicated. If } \\
\text { required, consider itraconazole } \\
\text { 200 mg daily [54] }\end{array}$ \\
\hline Paracoccidioidomycosis & $\begin{array}{l}\text { Itraconazole 200 mg once daily } \\
\text { for 12 months [77]. } \\
\text { Trimethoprim- } \\
\text { sulfamethoxazole may be } \\
\text { sufficient if already part of the } \\
\text { posttransplant prophylaxis } \\
\text { regimen }\end{array}$ & $\begin{array}{l}\text { Not routinely indicated. Can } \\
\text { follow with serial serology } \\
\text { titers. If required, consider } \\
\text { itraconazole 200 mg daily }\end{array}$ \\
\hline
\end{tabular}

\section{Treatment}

While itraconazole therapy alone may be sufficient to treat mild disease in patients with normal immunity, initial therapy with amphotericin B is recommended for all immunocompromised patients [54]. Lipid amphotericin formulations are preferred over the deoxycholate form due to the former's better side-effect profile, though unlike histoplasmosis there is no evidence that any of them are more efficacious.

Following 1-2 weeks of amphotericin and once the patient has demonstrated clinical improvement, the treatment regimen can be switched to an azole. Itraconazole is the preferred azole in most circumstances. No head-to-head comparison trials have been done within this class of drugs, but clinical trials using itraconazole to treat blastomycosis have generally shown better treatment responses than trials using fluconazole or ketoconazole [54, 55]. If fluconazole has to be used, it should be at doses of 400-800 mg/day, as outcomes appear significantly better than if a dose of $200-400 \mathrm{mg} /$ day is prescribed [56]. Blastomyces is susceptible to voriconazole, and the drug has been used successfully in small numbers of blastomycosis cases, often when there has been CNS involvement since, like fluconazole, voriconazole can achieve therapeutic concentrations within the brain [57]. Both posaconazole and isavuconazole also have activity against Blastomyces, but in vitro data and clinical experience are too limited for either drug to be 
recommended for anything beyond salvage therapy $[33,58]$. Extrapolating from data in AIDS patients with histoplasmosis, it is recommended that transplant recipients with blastomycosis should receive azole therapy for at least 12 months. The extent of the patient's immunosuppression is also an important factor to consider when deciding when to discontinue therapy [54]. The role of serial urine antigen titers is less well established for blastomycosis than for histoplasmosis, but clearance of the urinary antigen does appear to be correlated with treatment success [59].

Central nervous system involvement by Blastomyces is not common in transplant recipients. When it does occur, the optimal treatment strategy is unknown. Current recommendations are to give lipid formulations of amphotericin B for a prolonged period initially (4-6 weeks) and then to follow this with either itraconazole, fluconazole, or voriconazole [54]. While itraconazole is the azole of choice in general, its CNS penetration is far less than either fluconazole or voriconazole. The lack of headto-head data thus means that the optimal azole to choose with CNS blastomycosis is unclear.

\section{Prophylaxis}

There is limited data to guide decisions regarding prophylaxis in transplant recipients with a history of blastomycosis. Secondary prophylaxis may be reasonable in cases where the patients' immunosuppression regimen renders the patient profoundly immunosuppressed.

There is equally little information regarding the optimal therapy for recipients of organs from donors with a history of blastomycosis. Active disease in the donor is generally a contraindication to organ donation. Remote disease is not, however, and a suggested approach is outlined in Table 2 .

\section{Paracoccidioidomycosis}

\section{Disease Epidemiology}

Paracoccidioidomycosis is caused by one of five species: the Paracoccidioides lutzii and the P. brasiliensis species complex, consisting of species 1 (S1) and phylogenetic species 2, 3, and 4 (PS2, PS3, PS4) [60]. The disease is limited to Central and South America, and within this region, it is the most common of the endemic mycoses. Brazil accounts for $>80 \%$ of cases, but the disease is also known to many other countries in the region from Mexico to Argentina (Fig. 1) [61]. Sensitivity surveys using intradermal paracoccidioidin antigen showed a median exposure rate of approximately $25-35 \%$ in Brazil, rising as high as $50-75 \%$ among adults in highly endemic areas [61, 62]. Paracoccidioides has not often been cultured from environmental sources, but its favored environment appears to be tropical and subtropical rainforest areas, in regions with mild temperatures and good annual precipitation. These conditions also favor crops such as tobacco or coffee, 
and agricultural work in endemic regions is a known risk factor for acquiring the disease [61].

\section{Clinical Impact in Transplant Patients}

A study of pretransplant serologies of liver transplant recipients in an endemic area of Brazil revealed that $0.8 \%$ were seropositive for P. brasiliensis [63]. There are very few actual cases in the literature of paracoccidioidomycosis in SOT recipients however. A recent review counted a total of just ten, nine of which were in renal transplant recipients [64]. Furthermore, no case of paracoccidioidomycosis has ever been described in a HCT recipient. The low burden of this disease in transplant recipients is surprising and could reflect a combination of underdiagnosis, relatively limited access to transplants in endemic areas, and the use of trimethoprimsulfamethoxazole, a drug with known activity against Paracoccidioides, as part of routine posttransplant prophylaxis regimens. For a similar reason, most cases of paracoccidioidomycosis reported in SOT recipients have occurred after the first year of transplant, when trimethoprim-sulfamethoxazole prophylaxis is withdrawn [64]. Mortality in SOT recipients is hard to define given the small numbers involved, but the mortality rate seen to date (44\%) appears to be far higher than the 5-8\% mortality seen in the general population [65]. This would comport with what is known about paracoccidioidomycosis in human immunodeficiency virus (HIV)infected patients, in whom fungal burden, relapse rate, and overall mortality were all significantly greater than in patients without HIV coinfection [64].

\section{Pathogenesis and Clinical Manifestations}

In common with the other endemic mycoses, exposure occurs when the fungus' conidia are inhaled. Within the lung, those conidia that escape destruction by the local immune defenses develop into the organism's yeast form. As few as $2 \%$ of patients may develop symptomatic disease overall, reflecting the fact that host immunity is usually sufficient to quickly eliminate the infection [62]. A T-helper cell 1 (Th1) response seems necessary for this, with granulomas being the histological correlates of disease control [66]. By contrast, those patients who develop symptomatic disease may have an overtly Th2 immunologic profile, manifested by nonreactive paracoccidioidin skin tests but detectable antibodies, or an immunologically intermediate state lying between a Th1 and Th2 response [66].

When symptomatic disease does occur, it occurs as one of two syndromes. An acute/subacute form may develop within the first few weeks to months after exposure and is seen almost exclusively in children, adolescents, and adults $<30$ years old (hence its other name, "juvenile paracoccidioidomycosis"). This form is characterized by disseminated disease that predominantly involves the reticuloendothelial system, with lymphadenopathy, fever, anorexia, and weight loss being the most prominent symptoms. The lymph nodes are often massively enlarged, and the condition must be distinguished from lymphomas and disseminated tuberculosis. 

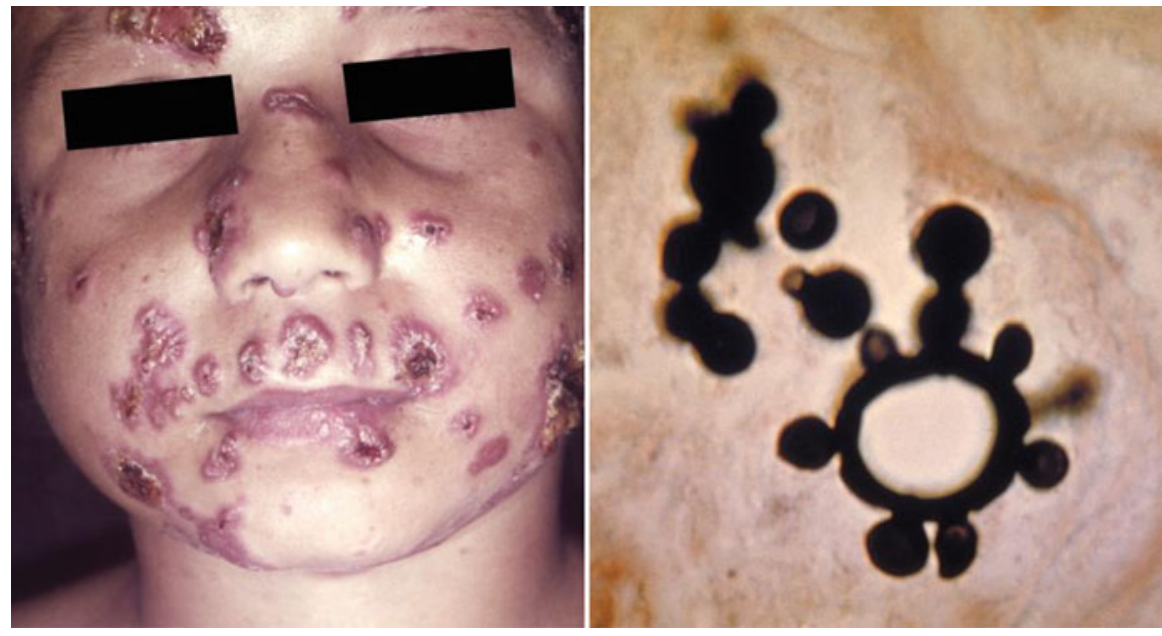

Fig. 4 Paracoccidioidomycosis. Left, typical skin lesions, consisting of nodules with central ulceration. Right, microscopy showing a classic "ship's wheel" configuration with a central yeast, and numerous daughter yeasts budding out circumferentially (methenamine silver stain). (Image credit: CDC/Dr. Martins Castro, Dr. Lucille K. Georg)

Anemia, hypergammaglobulinemia, and eosinophilia are also common, and hepatosplenomegaly occurs in just over one third of cases [67]. Unlike the chronic form, symptomatic pulmonary disease is very uncommon, despite the lungs being the route of entry and respiratory cultures often being positive.

The chronic form is much more common, accounting for $90 \%$ of symptomatic disease [62]. This represents a reactivation of previously controlled disease that can occur up to decades after the exposure [65]. There is a striking male predominance in the chronic form, with a male-female ratio as high as 22:1. This is possibly explained by the fact that $\beta$-estradiol inhibits the conversion of the Paracoccidioides conidia into the yeast form [62]. Although disease dissemination is also evident in the chronic form, the lungs are usually the chief focus. The most common symptoms are nonproductive cough and dyspnea, but the underlying pulmonary process is highly destructive over the long term, often leaving the patients with long-term pulmonary insufficiency. Despite this, symptoms and signs may be deceptively minimal. Chest X-ray or CT shows nodular and alveolar infiltrates, with a predilection for involvement of the mid- and lower zones [65]. The oral mucosa is also commonly affected, manifesting as painful ulcers that are most prominently seen around the gingiva and palate. The skin may be seeded by hematogenous dissemination, in which case verrucous or ulcerating papulonodular lesions are seen (Fig. 4). The adrenal glands are involved histologically in approximately $85 \%$ of cases, though overt Addison's disease is only seen in roughly 3\% [64, 68]. Lytic bone lesions are also sometimes seen, as is lymphadenopathy in a similar manner to the acute/subacute form. 


\section{Diagnosis}

The yeast form of Paracoccidioides has a distinctive microscopic appearance that when visualized allows for a direct diagnosis from sputum, scrapings of skin or mucosal lesions, tissue biopsy specimens, or abscess aspirates [62]. Characteristically, the microscopic appearance is of a central parent cell with multiple other daughter yeasts budding off it [23]. When just two daughter yeasts are present, the complex resembles a "Mickey Mouse head," and when the daughter yeasts surround the parent, a "ship's wheel" appearance is seen (Fig. 4). The yeasts are variably sized, at between 4 and $60 \mu$ [23].

The other principal method by which paracoccidioidomycosis can be diagnosed is by culture. In keeping with the other dimorphic mycoses, a positive result typically takes several weeks. Serology can also assist with the diagnosis. Quantitative immunodiffusion testing is the most widely used assay. Compared with many other types of Paracoccidioides serologic tests, this method has a lower rate of cross-reactivity with other organisms such as Histoplasma, Aspergillus, and Leishmania [69]. However, its sensitivity for P. lutzii is far lower than that for $P$. brasiliensis [70]. In addition, the sensitivity of serologic tests in general is also lower in immunosuppressed patients. This phenomenon has been documented in patients with paracoccidioidomycosis who were coinfected with HIV and may be expected in transplant recipients as well [64]. Serologic titers usually decline with successful treatment to levels of 1:2 or below, and thus following the titers sequentially is a useful adjunct to monitor treatment response [69].

Antigen tests targeting specific Paracoccidioides glycoproteins have been developed for use on serum, BAL fluid, and CSF, and these show great promise. In one diagnostic accuracy study that used the gp43 antigen, the test was 95\% sensitive and 97\% specific [71]. Unfortunately, these antigen tests are not yet commercially available. PCR assays have been developed but are similarly restricted to research rather than clinical settings [72].

\section{Treatment}

Paracoccidioides is susceptible to a wider range of drugs than any of the other dimorphic fungi. In addition to the azoles and polyenes, the sulfonamides and even terbinafine have substantial activity. Equally remarkably, no cases of resistance to any of the antifungals have yet been documented [69]. The choice of antifungal agent is therefore based on what clinical experience exists in the literature, taking into account the side-effect profiles and pharmacokinetic considerations of the various therapeutic options.

For mild to moderate disease, itraconazole is recommended [69]. The drug has been widely used and demonstrates good efficacy [73, 74]. For severe disease, initial treatment with amphotericin B is recommended, with a transition to itraconazole once the patient's clinical condition has begun to improve (usually after 2-4 weeks) [69]. Lipid formulations of amphotericin are preferred due to their lower 
nephrotoxicity. The duration of treatment is not well established and should be guided by improvement in clinical, serological, and radiological criteria. Durations of 9-18 months are typically used in the general population [69]. However, it is probably best to err toward the upper end of this range in transplant recipients, since immunocompromised patients tend to have higher rates of relapse [64].

When the above drugs are unavailable or contraindicated, trimethoprimsulfamethoxazole (co-trimoxazole) is a second-line option [69]. The drug has excellent bioavailability and an acceptable side-effect profile. There have been no randomized trials comparing this drug to any of the other treatment modalities, but most (though not all) retrospective data show equivalent rates of cure. However, side effects are more frequent, and a longer treatment duration (typically $\geq 2$ years) is required to prevent relapse $[75,76]$. Trimethoprim-sulfamethoxazole may also be the treatment of choice for paracoccidioidomycosis involving the central nervous system due to superior CNS penetration when compared to itraconazole.

The other azoles, such as fluconazole, posaconazole, voriconazole, and isavuconazole, all have activity against Paracoccidioides. In a small randomized trial, voriconazole was shown to be approximately as effective as itraconazole, albeit at the cost of slightly more side effects [74]. Fluconazole has not been adequately studied, though it appears to be significantly less potent in vitro as judged by MIC [74]. Posaconazole and isavuconazole have in vitro activity, though clinical experience is limited. In one trial, $8 / 10$ patients with paracoccidioidomycosis had at least a partially successful outcome when treated with isavuconazole as primary therapy [33]. As for other dimorphic fungi, the echinocandins have no therapeutic role.

\section{Prophylaxis}

Recipients should avoid travel to rural areas in Paracoccidioides endemic regions and should especially be counseled to avoid contact with agricultural activities there [77]. Potential donors with active disease should be excluded until they have been treated for at least 6 months. So far, there have not been any reported cases of transmission via infected allografts.

Recipients of organs from donors with previously treated disease should receive prophylaxis for 12 months, though this is based on expert opinion rather than clinical trial data [77]. Itraconazole can be used, as per Table 2. However, most patients will receive trimethoprim-sulfamethoxazole as part of their routine posttransplant prophylaxis, and although there is little data to guide clinicians in this scenario, this drug may be sufficient prophylaxis alone without adding itraconazole.

Given that only a handful of paracoccidioidomycosis cases have ever been described in transplant recipients, it is not clear whether posttreatment secondary prophylaxis is required. Provided the patient's immunosuppressant regimen is not too potent at the time of treatment completion, it may be reasonable to withhold secondary prophylaxis and instead monitor the patient both clinically and with serial serology titers, keeping in mind that serology likely has a lower sensitivity in transplant recipients. 
Table 3 Drug-drug interactions between antifungal drugs and common immunosuppressants and suggested dose immunosuppressant dose modifications

\begin{tabular}{|c|c|c|c|c|c|}
\hline Drug & $\begin{array}{l}\text { Tacrolimus } \\
\text { dose } \\
\text { adjustment }\end{array}$ & $\begin{array}{l}\text { Cyclosporine } \\
\text { dose } \\
\text { adjustment }\end{array}$ & $\begin{array}{l}\text { Mycophenolate } \\
\text { dose adjustment }\end{array}$ & $\begin{array}{l}\text { Sirolimus dose } \\
\text { adjustment }\end{array}$ & $\begin{array}{l}\text { Prednisone } \\
\text { dose } \\
\text { adjustment }\end{array}$ \\
\hline $\begin{array}{l}\text { Liposomal } \\
\text { amphotericin B }\end{array}$ & $\begin{array}{l}\text { No } \\
\text { significant } \\
\text { change }\end{array}$ & $\begin{array}{l}\text { No significant } \\
\text { change }\end{array}$ & $\begin{array}{l}\text { No significant } \\
\text { change }\end{array}$ & $\begin{array}{l}\text { No significant } \\
\text { change }\end{array}$ & $\begin{array}{l}\text { No } \\
\text { significant } \\
\text { change }\end{array}$ \\
\hline Fluconazole & $\begin{array}{l}\text { Tacrolimus } \\
\text { levels } \\
\text { increased. } \\
\text { Decrease } \\
\text { dose by } \\
50 \%\end{array}$ & $\begin{array}{l}\text { Cyclosporine } \\
\text { levels } \\
\text { increased. } \\
\text { Decrease } \\
\text { dose by } 50 \%\end{array}$ & $\begin{array}{l}\text { No significant } \\
\text { change required }\end{array}$ & $\begin{array}{l}\text { No significant } \\
\text { change }\end{array}$ & $\begin{array}{l}\text { No } \\
\text { significant } \\
\text { change }\end{array}$ \\
\hline Itraconazole & $\begin{array}{l}\text { Tacrolimus } \\
\text { levels } \\
\text { increased. } \\
\text { Monitor } \\
\text { level }\end{array}$ & $\begin{array}{l}\text { Cyclosporine } \\
\text { level } \\
\text { increased. } \\
\text { Monitor level }\end{array}$ & $\begin{array}{l}\text { No significant } \\
\text { change required }\end{array}$ & $\begin{array}{l}\text { Sirolimus level } \\
\text { increased. } \\
\text { Monitor level }\end{array}$ & $\begin{array}{l}\text { Unclear; } \\
\text { monitor for } \\
\text { side effects }\end{array}$ \\
\hline Voriconazole & $\begin{array}{l}\text { Tacrolimus } \\
\text { levels } \\
\text { increased. } \\
\text { Decrease } \\
\text { dose by } \\
66 \%\end{array}$ & $\begin{array}{l}\text { Cyclosporine } \\
\text { levels } \\
\text { increased. } \\
\text { Decrease } \\
\text { dose by } 50 \%\end{array}$ & $\begin{array}{l}\text { No significant } \\
\text { change }\end{array}$ & $\begin{array}{l}\text { Coadministration } \\
\text { contraindicated }\end{array}$ & $\begin{array}{l}\text { Unclear; } \\
\text { monitor for } \\
\text { side effects }\end{array}$ \\
\hline Posaconazole & $\begin{array}{l}\text { Tacrolimus } \\
\text { levels } \\
\text { increased. } \\
\text { Decrease } \\
\text { dose by } \\
66 \%\end{array}$ & $\begin{array}{l}\text { Cyclosporine } \\
\text { levels } \\
\text { increased. } \\
\text { Decrease } \\
\text { dose by } 25 \%\end{array}$ & $\begin{array}{l}\text { No significant } \\
\text { change }\end{array}$ & $\begin{array}{l}\text { Coadministration } \\
\text { contraindicated } \\
{[85]}\end{array}$ & $\begin{array}{l}\text { Unclear; } \\
\text { monitor for } \\
\text { side effects }\end{array}$ \\
\hline Isavuconazole & $\begin{array}{l}\text { Tacrolimus } \\
\text { levels } \\
\text { increased. } \\
\text { Decrease } \\
\text { dose } 25 \%\end{array}$ & $\begin{array}{l}\text { Cyclosporine } \\
\text { levels } \\
\text { increased } \\
\text { slightly. } \\
\text { Monitor } \\
\text { levels }\end{array}$ & $\begin{array}{l}\text { Mycophenolate } \\
\text { levels increased } \\
\text { mildly. Monitor } \\
\text { for clinical } \\
\text { effects }\end{array}$ & $\begin{array}{l}\text { Sirolimus levels } \\
\text { increased. } \\
\text { Decrease dose by } \\
50 \% \text { and monitor } \\
\text { level }\end{array}$ & $\begin{array}{l}\text { No } \\
\text { significant } \\
\text { change }\end{array}$ \\
\hline
\end{tabular}

\section{Common Antifungal Drugs Used to Treat the Endemic Mycoses}

\section{Itraconazole}

Itraconazole belongs to the azole family and comes in two forms, as a solution and as capsules. The solution form is preferred due to its better bioavailability and should be taken on an empty stomach. However, this form of the drug is associated with greater gastrointestinal side effects than the capsule. In addition to poorer bioavailability, the capsule also requires an acidic stomach $\mathrm{pH}$ for optimal drug absorption, 
precluding administration of proton pump inhibitors, histamine- 2 blockers, and antacids for several hours on either side of taking the capsule [78]. Furthermore, the capsule should be taken with food, rather than without food like the solution, and with an acidic beverage (e.g., soft drinks, or orange juice) to aid absorption $[78,79]$. If the solution is used, a lower dose of itraconazole is required, due to its much greater bioavailability.

Side effects include gastrointestinal upset and occasionally transaminitis. Itraconazole also has negative inotropic effects and in rare instances can cause heart failure, especially at high doses. Particular care should be taken in patients with underlying ventricular dysfunction. Despite poor CSF penetration, the drug has proven efficacy in CSF disease. Lastly, itraconazole is a both potent inhibitor and a substrate of the important CYP3A4 enzyme, meaning that it can be the cause or effect of multiple drug-drug interactions [80]. The enzymatic inhibition reaches its peak approximately 1 week after commencing itraconazole, and the effects can last up to a month after stopping the drug [81]. Therefore, any drugs whose levels are affected by itraconazole (e.g., the calcineurin inhibitors) should have their dosages adjusted and/or their levels checked around these times (Table 3).

The usual dose of itraconazole is $200 \mathrm{mg}$ three times a day for 2 days, followed by $200 \mathrm{mg}$ twice daily thereafter. However, care should be taken to make allowances for any drug-drug interactions. Checking drug levels is strongly recommended once the drug is at steady state (after 5-7 days).

\section{Fluconazole}

Fluconazole is an azole that is available in both intravenous and oral formulations. The oral form has excellent bioavailability $(\sim 90 \%)$, and its absorption is not significantly affected by food or gastric $\mathrm{pH}$. It is generally well-tolerated, with gastrointestinal side effects and occasional transaminitis being the chief complaints.

Fluconazole is a potent inhibitor of CYP2C9 and CYP2C19. However, it is only a moderate inhibitor of the important CYP3A4 isoenzyme, which means that drug-drug effects are often less troublesome than is seen with other azoles [80]. Nonetheless, like itraconazole, the same warnings apply with regard to drugs whose levels are affected by fluconazole (Table 3). Fluconazole is also a substrate of CYP3A4. CSF penetration is good $(>50 \%)$, which sometimes results in its selection to treat CNS disease despite its relatively weaker potency in most of the endemic mycoses.

The usual dose of fluconazole is $400 \mathrm{mg}$ daily. Because the drug is reliably well absorbed, drug levels do not need to be routinely checked.

\section{Amphotericin B}

Amphotericin B belongs to the polyene family and is only available as an intravenous drug. It comes in three formulations - a "conventional" deoxycholate form and 
two lipid formulations (liposomal amphotericin B and amphotericin B lipid complex). Nephrotoxicity is a major adverse effect of amphotericin, though the lipid forms are substantially less nephrotic than the deoxycholate formulation [82]. Amphotericin also commonly causes hypokalemia, hypomagnesemia, anemia, and phlebitis. A febrile infusion reaction is sometimes noted, especially if the drug is administered more quickly than recommended. This is not a true allergic reaction, and the patient can continue with subsequent doses of the regimen. However, slowing the infusion rate and administering acetaminophen, ibuprofen, hydrocortisone, or diphenhydramine prior to the infusion can help prevent subsequent similar febrile reactions [83]. Resistance to amphotericin B is exceptionally rare among the endemic fungi.

The usual doses of amphotericin vary by preparation. For liposomal amphotericin B, the conventional dose is $3-5 \mathrm{mg} / \mathrm{kg}$, whereas for amphotericin B lipid complex, it is $5 \mathrm{mg} / \mathrm{kg}$. "Conventional" (deoxycholate) amphotericin is administered at the lower dose of $1 \mathrm{mg} / \mathrm{kg}$.

\section{Conclusions}

Histoplasmosis, blastomycosis, and paracoccidioidomycosis are important threats to transplant recipients. The risk for these infections is primarily determined by geographic exposure. Diagnosis is made by combining various diagnostic modalities, with tissue biopsy often being needed for confirmation.

Treatment usually includes polyenes and azoles for prolonged treatment durations.

\section{Key Points}

- Endemic mycoses are restricted geographically.

- Transplant recipients are at increased risk for dissemination of endemic mycoses.

- Diagnosis of histoplasmosis, blastomycosis, and paracoccidioidomycosis is difficult, and often delayed.

- Combining various diagnostic modalities is often needed for accurate diagnosis of endemic mycoses.

- Treatment of severe disease should start with an intravenous polyene preparation.

- Azoles are the primary choice for maintenance regimens.

\section{References}

1. Mott DF. The opposite end of the spectrum - managing nongame species that are prospering. In: Proceedings of the workshop on management of nongame species and ecological communities. 1985. p. 151-8.

2. Krzysik AJ 1989 Birds in Human Modified Environments and Bird Damage Control Social Economic and Health Implications Technical Report N 9003 US Army Construction Engineering Research Laboratory USACERL 
3. Wheat LJ, Azar MM, Bahr NC, Spec A, Relich RF, Hage C. Histoplasmosis. Infect Dis Clin North Am. 2016;30(1):207-27.

4. Benedict K, Mody RK. Epidemiology of histoplasmosis outbreaks, United States, 1938-2013. Emerg Infect Dis. 2016;22(3):370-8.

5. Teixeira Mde M, Patane JS, Taylor ML, Gomez BL, Theodoro RC, de Hoog S, et al. Worldwide phylogenetic distributions and population dynamics of the genus histoplasma. PLoS Negl Trop Dis. 2016;10(6): $\mathrm{e} 0004732$.

6. Bahr NC, Antinori S, Wheat LJ, Sarosi GA. Histoplasmosis infections worldwide: thinking outside of the Ohio River valley. Curr Trop Med Rep. 2015;2(2):70-80.

7. Oladele RO, Ayanlowo OO, Richardson MD, Denning DW. Histoplasmosis in Africa: an emerging or a neglected disease? PLoS Negl Trop Dis. 2018;12(1):e0006046.

8. Ashbee HR, Evans EG, Viviani MA, Dupont B, Chryssanthou E, Surmont I, et al. Histoplasmosis in Europe: report on an epidemiological survey from the European Confederation of Medical Mycology Working Group. Med Mycol. 2008;46(1):57-65.

9. Edwards LB, Acquaviva FA, Livesay VT, Cross FW, Palmer CE. An atlas of sensitivity to tuberculin, PPD-B, and histoplasmin in the United States. Am Rev Respir Dis. 1969; 99(4 Suppl):1-132.

10. Maiga AW, Deppen S, Scaffidi BK, Baddley J, Aldrich MC, Dittus RS, et al. Mapping Histoplasma capsulatum exposure, United States. Emerg Infect Dis. 2018;24(10):1835-9.

11. Kauffman CA, Freifeld AG, Andes DR, Baddley JW, Herwaldt L, Walker RC, et al. Endemic fungal infections in solid organ and hematopoietic cell transplant recipients enrolled in the Transplant-Associated Infection Surveillance Network (TRANSNET). Transpl Infect Dis. 2014;16(2):213-24.

12. Cuellar-Rodriguez J, Avery RK, Lard M, Budev M, Gordon SM, Shrestha NK, et al. Histoplasmosis in solid organ transplant recipients: 10 years of experience at a large transplant center in an endemic area. Clin Infect Dis. 2009;49(5):710-6.

13. Gajurel K, Dhakal R, Deresinski S. Histoplasmosis in transplant recipients. Clin Transplant. 2017;31(10):e13087.

14. Assi M, Martin S, Wheat LJ, Hage C, Freifeld A, Avery R, et al. Histoplasmosis after solid organ transplant. Clin Infect Dis. 2013;57(11):1542-9.

15. Woods JP. Revisiting old friends: developments in understanding Histoplasma capsulatum pathogenesis. J Microbiol. 2016;54(3):265-76.

16. Nel JS, Bartelt LA, van Duin D, Lachiewicz AM. Endemic mycoses in solid organ transplant recipients. Infect Dis Clin North Am. 2018;32(3):667-85.

17. Wheat LJ, Smith EJ, Sathapatayavongs B, Batteiger B, Filo RS, Leapman SB, et al. Histoplasmosis in renal allograft recipients. Two large urban outbreaks. Arch Intern Med. 1983; 143(4):703-7.

18. Limaye AP, Connolly PA, Sagar M, Fritsche TR, Cookson BT, Wheat LJ, et al. Transmission of Histoplasma capsulatum by organ transplantation. N Engl J Med. 2000;343(16):1163-6.

19. Schwenk HT, Vo P, Moffitt K, Kehoe E, Blume E, Sharma T, et al. Allograft-transmitted Histoplasma capsulatum infection in a solid organ transplant recipient. J Pediatric Infect Dis Soc. 2013;2(3):270-3.

20. Wheat J, Wheat H, Connolly P, Kleiman M, Supparatpinyo K, Nelson K, et al. Cross-reactivity in Histoplasma capsulatum variety capsulatum antigen assays of urine samples from patients with endemic mycoses. Clin Infect Dis. 1997;24(6):1169-71.

21. Vergidis P, Walker RC, Kaul DR, Kauffman CA, Freifeld AG, Slagle DC, et al. False-positive Aspergillus galactomannan assay in solid organ transplant recipients with histoplasmosis. Transpl Infect Dis. 2012;14(2):213-7.

22. Assi MA, Sandid MS, Baddour LM, Roberts GD, Walker RC. Systemic histoplasmosis: a 15-year retrospective institutional review of 111 patients. Medicine (Baltimore). 2007; 86(3):162-9.

23. Guarner J, Brandt ME. Histopathologic diagnosis of fungal infections in the 21st century. Clin Microbiol Rev. 2011;24(2):247-80.

24. Ohno H, Tanabe K, Umeyama T, Kaneko Y, Yamagoe S, Miyazaki Y. Application of nested PCR for diagnosis of histoplasmosis. J Infect Chemother. 2013;19(5):999-1003. 
25. Muraosa Y, Toyotome T, Yahiro M, Watanabe A, Shikanai-Yasuda MA, Kamei K. Detection of Histoplasma capsulatum from clinical specimens by cycling probe-based real-time PCR and nested real-time PCR. Med Mycol. 2016;54(4):433-8.

26. Koepsell SA, Hinrichs SH, Iwen PC. Applying a real-time PCR assay for Histoplasma capsulatum to clinically relevant formalin-fixed paraffin-embedded human tissue. J Clin Microbiol. 2012;50(10):3395-7.

27. Wheat LJ, Freifeld AG, Kleiman MB, Baddley JW, McKinsey DS, Loyd JE, et al. Clinical practice guidelines for the management of patients with histoplasmosis: 2007 update by the Infectious Diseases Society of America. Clin Infect Dis. 2007;45(7):807-25.

28. Johnson PC, Wheat LJ, Cloud GA, Goldman M, Lancaster D, Bamberger DM, et al. Safety and efficacy of liposomal amphotericin B compared with conventional amphotericin B for induction therapy of histoplasmosis in patients with AIDS. Ann Intern Med. 2002;137(2):105-9.

29. Wheat J, Hafner R, Korzun AH, Limjoco MT, Spencer P, Larsen RA, et al. Itraconazole treatment of disseminated histoplasmosis in patients with the acquired immunodeficiency syndrome. AIDS Clinical Trial Group. Am J Med. 1995;98(4):336-42.

30. Wheat LJ, Connolly P, Smedema M, Brizendine E, Hafner R, AIDS Clinical Trials Group and the Mycoses Study Group of the National Institute of Allergy and Infectious Diseases, et al. Emergence of resistance to fluconazole as a cause of failure during treatment of histoplasmosis in patients with acquired immunodeficiency disease syndrome. Clin Infect Dis. 2001;33(11): $1910-3$.

31. Wheat J, MaWhinney S, Hafner R, McKinsey D, Chen D, Korzun A, et al. Treatment of histoplasmosis with fluconazole in patients with acquired immunodeficiency syndrome. National Institute of Allergy and Infectious Diseases Acquired Immunodeficiency Syndrome Clinical Trials Group and Mycoses Study Group. Am J Med. 1997;103(3):223-32.

32. Wheat LJ, Connolly P, Smedema M, Durkin M, Brizendine E, Mann P, et al. Activity of newer triazoles against Histoplasma capsulatum from patients with AIDS who failed fluconazole. J Antimicrob Chemother. 2006;57(6):1235-9.

33. Thompson GR 3rd, Rendon A, Ribeiro Dos Santos R, Queiroz-Telles F, Ostrosky-Zeichner L, Azie N, et al. Isavuconazole treatment of cryptococcosis and dimorphic mycoses. Clin Infect Dis. 2016;63(3):356-62.

34. Hage CA, Connolly P, Horan D, Durkin M, Smedema M, Zarnowski R, et al. Investigation of the efficacy of micafungin in the treatment of histoplasmosis using two North American strains of Histoplasma capsulatum. Antimicrob Agents Chemother. 2011;55(9):4447-50.

35. Goldman M, Zackin R, Fichtenbaum CJ, Skiest DJ, Koletar SL, Hafner R, et al. Safety of discontinuation of maintenance therapy for disseminated histoplasmosis after immunologic response to antiretroviral therapy. Clin Infect Dis. 2004;38(10):1485-9.

36. McKinsey DS, Wheat LJ, Cloud GA, Pierce M, Black JR, Bamberger DM, et al. Itraconazole prophylaxis for fungal infections in patients with advanced human immunodeficiency virus infection: randomized, placebo-controlled, double-blind study. National Institute of Allergy and Infectious Diseases Mycoses Study Group. Clin Infect Dis. 1999;28(5):1049-56.

37. Saccente M, Woods GL. Clinical and laboratory update on blastomycosis. Clin Microbiol Rev. 2010;23(2):367-81.

38. Klein BS, Vergeront JM, DiSalvo AF, Kaufman L, Davis JP. Two outbreaks of blastomycosis along rivers in Wisconsin. Isolation of Blastomyces dermatitidis from riverbank soil and evidence of its transmission along waterways. Am Rev Respir Dis. 1987;136(6):1333-8.

39. Klein BS, Vergeront JM, Weeks RJ, Kumar UN, Mathai G, Varkey B, et al. Isolation of Blastomyces dermatitidis in soil associated with a large outbreak of blastomycosis in Wisconsin. N Engl J Med. 1986;314(9):529-34.

40. Chakrabarti A, Slavin MA. Endemic fungal infections in the Asia-Pacific region. Med Mycol. 2011;49(4):337-44.

41. Baily GG, Robertson VJ, Neill P, Garrido P, Levy LF. Blastomycosis in Africa: clinical features, diagnosis, and treatment. Rev Infect Dis. 1991;13(5):1005-8. 
42. Linder KAKC, Miceli M. Pulmonary blastomycosis in a hematopoietic cell transplant recipient. Infect Dis Clin Pract. 2016;24(6): e71-3.

43. Grim SA, Proia L, Miller R, Alhyraba M, Costas-Chavarri A, Oberholzer J, et al. A multicenter study of histoplasmosis and blastomycosis after solid organ transplantation. Transpl Infect Dis. 2012;14(1):17-23.

44. Gauthier GM, Safdar N, Klein BS, Andes DR. Blastomycosis in solid organ transplant recipients. Transpl Infect Dis. 2007;9(4):310-7.

45. Wuthrich M, Finkel-Jimenez B, Brandhorst TT, Filutowicz HI, Warner T, Klein BS. Analysis of non-adhesive pathogenic mechanisms of BAD1 on Blastomyces dermatitidis. Med Mycol. 2006;44(1):41-9.

46. Ehni W. Endogenous reactivation in blastomycosis. Am J Med. 1989;86(6 Pt 2):831-2.

47. Kauffman CA, Miceli MH. Histoplasmosis and blastomycosis in solid organ transplant recipients. J Fungi (Basel). 2015;1(2):94-106.

48. Smith JA, Gauthier G. New developments in blastomycosis. Semin Respir Crit Care Med. 2015;36(5):715-28.

49. Smith JA, Kauffman CA. Blastomycosis. Proc Am Thorac Soc. 2010;7(3):173-80.

50. Chapman SW, Lin AC, Hendricks KA, Nolan RL, Currier MM, Morris KR, et al. Endemic blastomycosis in Mississippi: epidemiological and clinical studies. Semin Respir Infect. 1997;12(3):219-28.

51. Martynowicz MA, Prakash UB. Pulmonary blastomycosis: an appraisal of diagnostic techniques. Chest. 2002;121(3):768-73.

52. Durkin M, Witt J, Lemonte A, Wheat B, Connolly P. Antigen assay with the potential to aid in diagnosis of blastomycosis. J Clin Microbiol. 2004;42(10):4873-5.

53. Frost HM, Novicki TJ. Blastomyces antigen detection for diagnosis and management of blastomycosis. J Clin Microbiol. 2015;53(11):3660-2.

54. Chapman SW, Dismukes WE, Proia LA, Bradsher RW, Pappas PG, Threlkeld MG, et al. Clinical practice guidelines for the management of blastomycosis: 2008 update by the Infectious Diseases Society of America. Clin Infect Dis. 2008;46(12):1801-12.

55. Pappas PG, Bradsher RW, Kauffman CA, Cloud GA, Thomas CJ, Campbell GD Jr, et al. Treatment of blastomycosis with higher doses of fluconazole. The National Institute of Allergy and Infectious Diseases Mycoses Study Group. Clin Infect Dis. 1997;25(2):200-5.

56. Pappas PG, Bradsher RW, Chapman SW, Kauffman CA, Dine A, Cloud GA, et al. Treatment of blastomycosis with fluconazole: a pilot study. The National Institute of Allergy and Infectious Diseases Mycoses Study Group. Clin Infect Dis. 1995;20(2):267-71.

57. Bariola JR, Perry P, Pappas PG, Proia L, Shealey W, Wright PW, et al. Blastomycosis of the central nervous system: a multicenter review of diagnosis and treatment in the modern era. Clin Infect Dis. 2010;50(6):797-804.

58. Sugar AM, Liu XP. In vitro and in vivo activities of SCH 56592 against Blastomyces dermatitidis. Antimicrob Agents Chemother. 1996;40(5):1314-6.

59. Mongkolrattanothai K, Peev M, Wheat LJ, Marcinak J. Urine antigen detection of blastomycosis in pediatric patients. Pediatr Infect Dis J. 2006;25(11):1076-8.

60. Theodoro RC, Bagagli E, Oliveira C. Phylogenetic analysis of PRP8 intein in Paracoccidioides brasiliensis species complex. Fungal Genet Biol. 2008;45(9):1284-91.

61. Martinez R. Epidemiology of paracoccidioidomycosis. Rev Inst Med Trop Sao Paulo. 2015; 57(Suppl 19):11-20.

62. Travassos LR, Taborda CP, Colombo AL. Treatment options for paracoccidioidomycosis and new strategies investigated. Expert Rev Anti Infect Ther. 2008;6(2):251-62.

63. Boin ID, Boteon YL, Stucchi RS, Pereira MI, Portugal TC, Udo EY. Serological profile of pretransplantation liver patients. Transplant Proc. 2010;42(2):491-3.

64. de Almeida JN Jr, Pecanha PM, Colombo AL. Paracoccidioidomycosis in immunocompromised patients: a literature review. J Fungi (Basel). 2018;5(1).

65. Brummer E, Castaneda E, Restrepo A. Paracoccidioidomycosis: an update. Clin Microbiol Rev. 1993;6(2):89-117. 
66. Fortes MR, Miot HA, Kurokawa CS, Marques ME, Marques SA. Immunology of paracoccidioidomycosis. An Bras Dermatol. 2011;86(3):516-24.

67. Pereira RM, Bucaretchi F, Barison Ede M, Hessel G, Tresoldi AT. Paracoccidioidomycosis in children: clinical presentation, follow-up and outcome. Rev Inst Med Trop Sao Paulo. 2004;46(3):127-31.

68. Onate JM, Tobon AM, Restrepo A. Adrenal gland insufficiency secondary to paracoccidioidomycosis. Biomedica. 2002;22(3):280-6.

69. Shikanai-Yasuda MA, Mendes RP, Colombo AL, Queiroz-Telles F, Kono ASG, Paniago AMM, et al. Brazilian guidelines for the clinical management of paracoccidioidomycosis. Rev Soc Bras Med Trop. 2017;50(5):715-40.

70. Batista J Jr, de Camargo ZP, Fernandes GF, Vicentini AP, Fontes CJ, Hahn RC. Is the geographical origin of a Paracoccidioides brasiliensis isolate important for antigen production for regional diagnosis of paracoccidioidomycosis? Mycoses. 2010;53(2):176-80.

71. Marques da Silva SH, Colombo AL, Blotta MH, Lopes JD, Queiroz-Telles F, Pires de Camargo Z. Detection of circulating gp43 antigen in serum, cerebrospinal fluid, and bronchoalveolar lavage fluid of patients with paracoccidioidomycosis. J Clin Microbiol. 2003;41(8): $3675-80$.

72. Gomes GM, Cisalpino PS, Taborda CP, de Camargo ZP. PCR for diagnosis of paracoccidioidomycosis. J Clin Microbiol. 2000;38(9):3478-80.

73. Naranjo MS, Trujillo M, Munera MI, Restrepo P, Gomez I, Restrepo A. Treatment of paracoccidioidomycosis with itraconazole. J Med Vet Mycol. 1990;28(1):67-76.

74. Queiroz-Telles F, Goldani LZ, Schlamm HT, Goodrich JM, Espinel-Ingroff A, Shikanai-Yasuda MA. An open-label comparative pilot study of oral voriconazole and itraconazole for long-term treatment of paracoccidioidomycosis. Clin Infect Dis. 2007;45(11):1462-9.

75. Cavalcante Rde S, Sylvestre TF, Levorato AD, de Carvalho LR, Mendes RP. Comparison between itraconazole and cotrimoxazole in the treatment of paracoccidiodomycosis. PLoS Negl Trop Dis. 2014;8(4):e2793.

76. Borges SR, Silva GM, Chambela Mda C, Oliveira Rde V, Costa RL, Wanke B, et al. Itraconazole vs. trimethoprim-sulfamethoxazole: a comparative cohort study of 200 patients with paracoccidioidomycosis. Med Mycol. 2014;52(3):303-10.

77. Abdala E, Miller R, Pasqualotto AC, Munoz P, Colombo AL, Cuenca-Estrella M. Endemic fungal infection recommendations for solid-organ transplant recipients and donors. Transplantation. 2018;102(2S Suppl 2):S52-9.

78. Van Peer A, Woestenborghs R, Heykants J, Gasparini R, Gauwenbergh G. The effects of food and dose on the oral systemic availability of itraconazole in healthy subjects. Eur J Clin Pharmacol. 1989;36(4):423-6.

79. Jaruratanasirikul S, Kleepkaew A. Influence of an acidic beverage (Coca-Cola) on the absorption of itraconazole. Eur J Clin Pharmacol. 1997;52(3):235-7.

80. Venkatakrishnan K, von Moltke LL, Greenblatt DJ. Effects of the antifungal agents on oxidative drug metabolism: clinical relevance. Clin Pharmacokinet. 2000;38(2):111-80.

81. Dodds-Ashley E. Management of drug and food interactions with azole antifungal agents in transplant recipients. Pharmacotherapy. 2010;30(8):842-54.

82. Wong-Beringer A, Jacobs RA, Guglielmo BJ. Lipid formulations of amphotericin B: clinical efficacy and toxicities. Clin Infect Dis. 1998;27(3):603-18.

83. Gigliotti F, Shenep JL, Lott L, Thornton D. Induction of prostaglandin synthesis as the mechanism responsible for the chills and fever produced by infusing amphotericin B. J Infect Dis. 1987;156(5):784-9.

84. Singh N, Huprikar S, Burdette SD, Morris MI, Blair JE, Wheat LJ, et al. Donor-derived fungal infections in organ transplant recipients: guidelines of the American Society of Transplantation, infectious diseases community of practice. Am J Transplant. 2012;12(9):2414-28.

85. Merck \& Co. Inc. Noxafil ${ }^{\mathbb{R}}$ (posaconazole) injection $18 \mathrm{mg} / \mathrm{mL}$ Noxafil ${ }^{\circledR}$ (posaconazole) delayed-release tablets $100 \mathrm{mg}$ Noxafil ${ }^{\circledR}$ (posaconazole) oral suspension $40 \mathrm{mg} / \mathrm{mL} .2015$. 
86. Centers for Disease Control and Prevention. Fungal infections - protect your health. Centers for Disease Control and Prevention; 2019. https:/www.cdc.gov/features/fungalinfections/ index.html

87. Schwartz S, Kontoyiannis DP, Harrison T, Ruhnke M. Advances in the diagnosis and treatment of fungal infections of the CNS. Lancet Neurol. 2018;17(4):362-72. 